\title{
OPTIMIZATION OF CULTURE CONDITIONS FOR SQUALENE PRODUCTION AND SQUALENE EXTRACTION METHOD OF Thraustochytrium sp. TN22
}

\author{
Hoang Thi Minh Hien ${ }^{1, *}$, Le Thi Thom ${ }^{1,2}$, Nguyen Cam Ha ${ }^{1,2}$, \\ Hoang Thi Lan Anh ${ }^{1}$, Dang Diem Hong ${ }^{1,2,3}$ \\ ${ }^{1}$ Institute of Biotechnology, VAST \\ ${ }^{2}$ Graduate University of Science and Technology, VAST \\ ${ }^{3}$ Thuyloi University, Ha Noi, Vietnam
}

Received 9 April 2020, accepted 20 September 2020

\begin{abstract}
Squalene, a natural triterpene with important roles as antioxidant, skin hydrating, cardioprotection and detoxifier, has attracted the attention of researchers in the world. This study investigated the optimal culture conditions for squalene production and to develop a method for squalene extraction and purification from cell suspension of Thraustochytrium sp. TN22. The results showed that squalene production by the strain Thraustochytrium sp. TN22 was optimum at $2 \%$ glucose, $0.5 \%$ yeast extract and $0,14 \%$ mixture of vitamins $\left(\mathrm{B}_{1}, \mathrm{~B}_{6}\right.$ and $\left.\mathrm{B}_{12}\right)$ at $28{ }^{\circ} \mathrm{C}$ for 2 days of cultivation. At the optimum conditions, the dry biomass, squalene content and productivity were approximately $9.3 \mathrm{~g} / \mathrm{L}, 9.9 \mathrm{mg} / \mathrm{g} \mathrm{DCW}$ and $95.3 \mathrm{mg} / \mathrm{L}$, respectively. Time-dependence on cell lysis and extraction solvents were selected as the extraction parameters. The obtained results showed that the highest squalene production of $178.1 \mathrm{mg} / 100$ g biomass was obtained in cell lysate at alkaline medium $(\mathrm{pH}=10)$, at $6{ }^{\circ} \mathrm{C}$ for 6 hours and $\mathrm{n}$ hexan was the best solvent for squalene extraction. Squalene was then purified on silica gel column using n-hexan as the mobile phase and $90 \%$ purity of squalene was archived. Our obtained results are promising for the commercial productions of various value-added compounds from species belong to the genus Thrautochytrium in Vietnam.
\end{abstract}

Keywords: Thraustochytrium, culture, isolation, squalene, production.

Citation: Hoang Thi Minh Hien, Le Thi Thom, Nguyen Cam Ha, Hoang Thi Lan Anh, Dang Diem Hong, 2020. Optimization of culture conditions for squalene production and squalene extraction method of Thraustochytrium sp. TN22. Academia Journal of Biology, 42(3): 73-85. https://doi.org/10.15625/2615-9023/v42n4.14978

*Corresponding author email: hmhien@ibt.ac.vn

C2020 Vietnam Academy of Science and Technology (VAST) 


\section{INTRODUCTION}

Squalene is a natural lipid belonging to the terpenoid family and can impact human health. The most common source of squalene is liver oil of deep-sea sharks and whales. Sources for squalene production (primarily in vegetable oils) are identified in amaranth seed, rice bran, wheat germ and olives. All plants and animals produce squalene as a biochemical intermediate or precursor for biosynthesis of steroid hormones in eukaryotic cells, plants, animals and human (Pollier et al., 2019). Squalene has wide applications ranging from cosmetic industry to medical and pharmaceutical sector, owing to its broad functionalities. Furthermore, squalene is also found to exhibit radioprotective and cardioprotective activities (Spanova \& Daum, 2011). Additionally, squalene is also a value-added product besides algal biodiesel (Hoang et al., 2014). The global demand for squalene has been increasing over the past decade, amounting to around 4,000 tons in 2019 (Tran et al., 2020), and could not be met solely by extracting it from the liver of marine animals; an approach that is severely affecting marine ecosystems. Plant oils are known to be capable of producing adequate quantities of squalene for pharmaceutical or nutraceutical industrial applications (Popa et al., 2015). However, recent researches suggested that thraustochytrids could serve also for largescale commercial generation of squalene (Xie et al., 2017).

Thraustochytrid are heterotrophic marine oleaginous microorganisms capable of synthesizing high amounts of DHA, as well as other nutraceutical compounds such as squalene in their cellular compartment (Hoang et al., 2018; Patel et al., 2019). It is reported that the squalene contents in species belonging to thraustochytrids range from 0.18 to $84 \mathrm{mg} / \mathrm{g}$ of dry cell weight (DCW) (Li et al., 2009; Hoang et al., 2014; Otagiri et al., 2017; Hoang et al., 2018; Patel et al., 2019).
Some thraustochytrids contain a high content of squalene, such as Thraustochytrid ACEM $6063 \quad(0.1 \mathrm{mg} / \mathrm{g}$ of biomass), Aurantiochytrium mangrovei FB 1 (0.162 $\mathrm{mg} / \mathrm{g}$ of biomass), Schizochytrium mangrovei PQ6 (98.07 mg/g of lipid), Aurantiochytrium sp. 18W-3a (171 mg/g DCW) and Aurantiochytrium sp. (318 mg/g DCW) (Patel et al., 2019). In Vietnam, Thraustochytrium sp. strain TN22 was successful isolated from Thi Nai marsh, Binh Dinh Province, Vietnam (Hoang Lan Anh et al., 2010). Results of morphological characteristic and molecular analysis showed that Thraustochytrium sp. TN22 belongs to genus Thraustochytrium, but it is not yet known exactly which species it belongs to. Thraustochytrium sp. TN22 grew well in Bajpai medium with cell density and dry cell weight (DCW) of $241.44 \times 10^{6}$ cells $/ \mathrm{mL}$ and $4.79 \mathrm{~g} / \mathrm{L}$, respectively after 5 days of cultivation. The total lipid content and essential PUFAs, such as docosahexaenoic acid (DHA, C22: 6n-3), docosapentaenoic acid (DPA, C22: 5n-6) and eicosapentaenoic acid (EPA, C20: 5n-3) of the strain were $5.06 \%$ of fresh weight, $35.17 \%, 12.18 \%$ and $1.097 \%$ of total fatty acid, respectively, after 4 days of cultivation in 1 liter flask. In addition, the strain of TN22 showed to accumulate significant amount of carotenoid (up to 5.2 $\mathrm{mg} / \mathrm{kg}$ of DCW) and squalene (up to $22 \mathrm{mg} / \mathrm{g}$ of DCW) (Hoang Lan Anh et al., 2010; Dinh Thi Ngoc Mai et al., 2013). Jiang et al. (2004) reported that the squalene level almost depends on the culture conditions. In present study, the optimal conditions for high squalene production of Thraustochytrium sp. TN22 were investigated. Additionally, the methods for extraction and purification of squalene from cell suspension of this strain were developed.

\section{MATERIALS AND METHODS}

\section{The strain and inoculation}

The microalgae Thraustochytrium sp. strain TN22 isolated from Thi Nai, Binh Dinh, 
Vietnam (with accession number TTNBD02) which was deposited at Department of Algal Biotechnology, Institute of Biotechnology, Vietnam Academy of Science and Technology was used in this study. This strain was kept at $25-28{ }^{\circ} \mathrm{C}$ on glucose-peptoneyeast extract (GPY) medium which contained glucose $3 \mathrm{~g} / \mathrm{L}$, polypeptone $2 \mathrm{~g} / \mathrm{L}$, yeast extract $1 \mathrm{~g} / \mathrm{L}$, agar $15 \mathrm{~g} / \mathrm{L}$, and artificial seawater (ASW) $17.5 \mathrm{~g} / \mathrm{L}$ as described by Hoang Thi Lan Anh et al. (2010). A single colony cultivated on a plate was picked up and transferred to a $250 \mathrm{~mL}$ Erlenmeyer flask containing $100 \mathrm{~mL}$ of the modified Bajpai medium (Bajpai et a., 1991; Hoang et al., 2010) ( $\mathrm{NaCl} 25 \mathrm{~g} / \mathrm{L}, \mathrm{MgSO}_{4} .7 \mathrm{H}_{2} \mathrm{O} 5 \mathrm{~g} / \mathrm{L}, \mathrm{KCl}$ $1 \mathrm{~g} / \mathrm{L}, \mathrm{KH}_{2} \mathrm{PO}_{4} 0.1 \mathrm{~g} / \mathrm{L}, \mathrm{CaCO}_{3} 0.2 \mathrm{~g} / \mathrm{L}$, $\left(\mathrm{NH}_{4}\right)_{2} \mathrm{SO}_{4} 0.2 \mathrm{~g} / \mathrm{L}$, sodium glutamate $2 \mathrm{~g} / \mathrm{L}$, $\mathrm{NaHCO}_{3} 0.1 \mathrm{~g} / \mathrm{L}$, glucose $20 \mathrm{~g} / \mathrm{L}$, yeast extract $10 \mathrm{~g} / \mathrm{L}$ ) and incubated for 4 days at 28 ${ }^{\circ} \mathrm{C}$ with shaking at $150 \mathrm{rpm}$ for the preparation of a seed culture. The $4 \mathrm{~mL}$ of the seed culture were then transferred to $500 \mathrm{~mL}$ Erlenmeyer flasks containing $200 \mathrm{~mL}$ of the modified Bajpai and incubated at $28{ }^{\circ} \mathrm{C}$ with continuous shaking at $200 \mathrm{rpm}$.

\section{Optimization of culture conditions}

The growth and squalene production of Thraustochytrium sp. TN22 were investigated under four different parameters (carbon sources, glucose concentration, yeast extract concentrations and vitamin mixture). For carbon sources, cells were growth in the modified Bajpai medium with glucose, maltose, or starch at concentration of $2 \%$. To test the effect of glucose concentrations, cells were growth in the modified Bajpai medium with glucose in different concentrations of $1 \%, 2 \%, 3 \%$ and $4 \%$. To investigate the effect of yeast extract concentration, the cells were grown in M12 basal medium with $0.25 \%, 5 \%$, $1 \%$ and $1.5 \%$ yeast extract. To perform the effect of the addition of vitamins, the cells were grown in M12 basal medium with and without supplementary addition of $0.14 \%$ vitamin mixture (vitamin $\mathrm{B}_{1} 45 \mathrm{~g} / \mathrm{L}$, vitamin
$\mathrm{B}_{6} 45 \mathrm{~g} / \mathrm{L}$ and vitamin $\mathrm{B}_{12} 0.25 \mathrm{~g} / \mathrm{L}$ ). Each parameter was tested separately with other parameters was kept constant. The culture conditions with the greatest growth were statistically validated and set as the optimal conditions. Cells were harvested after 1, 2, 3, and 5 days of cultivation by centrifuging at $3000 \mathrm{rpm}$ for $10 \mathrm{~min}$ and keep at $(-) 20^{\circ} \mathrm{C}$ until use for growth and squalene accumulation analysis.

\section{Analytical methods under optimum conditions}

Cell growth was determined by measuring DCW as described in our previous study (Dang Diem Hong \& Hoang Thi Lan Anh, 2016).

The dried biomass of Thraustochytrium sp. TN22 cultured in the optimal culture conditions was used for squalene extraction following to two steps process. The first step was lipid extraction as in the report of Bligh and Dyer (1956) with some modifications as described by Hoang et al. (2014). The second step was to remove the saponifiable lipid from total lipid. Briefly, total lipid was placed in a Pyrex flask and mixed with a solution of $5 \%$ $(\mathrm{w} / \mathrm{v})$ potassium hydroxide in methanol-water $(4: 1, v / v)$. The reaction mixture was heated and maintained at $60{ }^{\circ} \mathrm{C}$ for 3 hours and well mixed throughout the experiment. After the reaction, following a cool down time, $4 \mathrm{~mL}$ of distilled water was added. The unsaponifiable lipid was extracted three times with a mixture of n-hexane-chloroform $(4: 1, \mathrm{v} / \mathrm{v})(10 \mathrm{~mL}$ each time). The entire unsaponifiable lipid in n-hexane layer was combined and the solvent was evaporated to dryness under nitrogen gas. Squalene was separated from unsaponifiable lipid by thin-layer chromatography and analyzed as described by Hoang et al. (2014).

\section{Extration of squalene from cell suspensions of Thraustochytrium $\mathrm{sp}$. TN22}

The cell suspensions of Thraustochytrium sp. TN22 was removed from the Erlenmeyer flask, and then concentrated to $100 \mathrm{~g} / \mathrm{L}$ by settling for 2 hours and removing the medium. 
The biomass was kept stirring at $150 \mathrm{rpm}$ in a $200 \mathrm{~mL}$ Erlenmeyer flask and heated to $60{ }^{\circ} \mathrm{C}$. The $\mathrm{pH}$ was then adjusted to 10 with $45 \%$ potassium hydroxide. These conditions were kept for 1, 2, 4, 6 and $8 \mathrm{~h}$ in order to achieve complete alkaline lysis. The quality of the lysis was monitored under a light microscopy (Olympus CX21, Tokyo, Japan) and by sample centrifugation $(2 \mathrm{~min}, 10,000 \mathrm{~g})$. At the end of lysis, one volume of ethanol was added to the flask maintained at $45{ }^{\circ} \mathrm{C}$ and stirred for $10 \mathrm{~min}$. One volume of $\mathrm{n}$-hexane; methanol: chloroform $(2: 1, \mathrm{v} / \mathrm{v})$; or petroleum ether was then added to the flask and kept stirring for $30 \mathrm{~min}$. The mixture was then centrifuged in order to separate the solvent fraction which was stored in the other Erlenmeyer flask. The aqueous fraction was again brought together with one volume of above organic solvents so as to perform a second extraction according to the same scheme as previously in order to increase the extraction yield. The solvent fractions were combined and evaporate in a rotary evaporator $\left(70{ }^{\circ} \mathrm{C}\right)$. Squalene was then separated from extracted unsaponifiable lipid by thin-layer chromatography and analyzed as described by Hoang et al. (2014).

\section{Purification and structural identification of squalene}

The crude squalene were further purified by column chromatography on a silica gel 60 (24 g, 70e230 mesh ASTM, EMD Millipore, MA, USA) column. A solution of $0.2 \mathrm{~g}$ of the crude squalene in $5 \mathrm{~mL}$ of $\mathrm{n}$-hexane was loaded and eluted with $n$-hexane at a flow rate of approximately $1.0 \mathrm{~mL} / \mathrm{min}$. Test tubes $(10$ $\mathrm{mL}$ with screw cap) were used for fraction collecting and thin layer chromatography (TLC) was used for squalene detection. The fractions containing squalene were combined and evaporated up to dryness in vacuum condition by vacuum evaporator to obtain the purified squalene.

The structure of purified squalene was confirmed by the nuclear magnetic resonance (NMR) spectroscopy. NMR experiments were performed using a Bruker Avance e $500 \mathrm{MHz}$ spectrometer (Bruker, Karlsruhe, Germany) at operating frequencies of $500 \mathrm{MHz}\left({ }^{1} \mathrm{H}\right)$ and $125 \mathrm{MHz}\left({ }^{13} \mathrm{C}\right)$ at the Institute of Chemistry, VAST, Vietnam.

\section{Statistics}

The data were analysed by a one-way ANOVA and a Tukey-Kramer post-hoc analysis was used to detect significant differences between the means at a level of $\mathrm{P}$ $<0.05$.

\section{RESULTS AND DISCUSSION \\ Optimization of culture conditions}

The effects of various culture conditions such as carbon sources, glucose concentration, yeast extract concentrations and vitamin mixture on the cell growth, lipid and squalene accumulation of Thraustochytrium sp. TN22 were examined.

\section{Carbon source test}

It is acknowledged that Thraustochytrium sp. was able to grow on maltose, soluble starch (starch), and glucose; by contrast, fructose and sucrose did not support the growth (Shene et al., 2019). According to Nakazawa et al. (2012), Jiang et al. (2004), Chen et al. (2010), Patel et al. (2019), squalene content of thraustochytrids was the highest at $2 \%$ glucose but production per liter was not significantly different at concentrations from $2 \%$ to $6 \%$. Therefore, glucose, maltose and starch at concentration of $2 \%$ were used to investigate the effect of carbon sources on cell growth and squalene production of the strain TN22 in this study (Fig. 1).

Figure 1 showed that when glucose was use as carbon sources, high levels of DCW and squalene content were obtained. Carbon sources such as maltose and starch were less effective for both of cell growth and squalene accumulation. The maximum DCW was reached at $8.6 \mathrm{~g} / \mathrm{L}$ on day $3^{\text {th }}$, while squalene content and production reached maximum value of $5.9 \mathrm{mg} / \mathrm{g}$ of DCW and $44.7 \mathrm{mg} / \mathrm{L}$ on second cultivation day, respectively. 

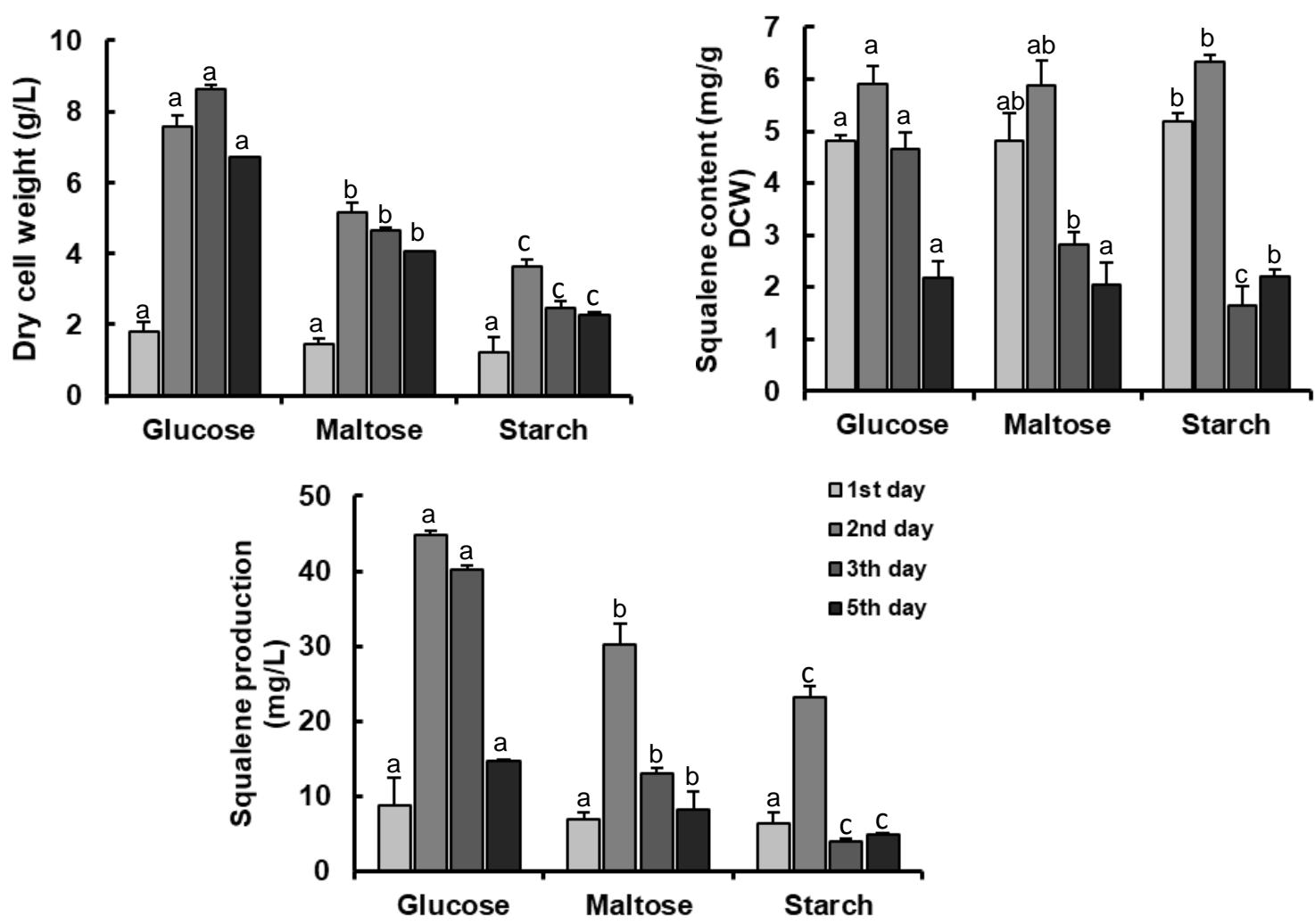

Figure 1. Effect of carbon sources on cell growth and squalene accumulation in Thraustochytrium $\mathrm{sp}$. TN22. Data represent the means \pm SE $(\mathrm{n}=3)$. a,b,c: Values in a line not sharing a common superscript differ significantly at $P<0.05$

\section{Glucose concentration test}

To obtain a cell growth and squalene accumulation, the effect of glucose concentration was investigated with various concentrations of glucose ranging from $1 \%$ to $4 \%$. As shown in Fig. 2, the cell growth of Thraustochytrium sp. TN22 increased when glucose concentration was over $1 \%$. The growth rate of TN22 strain achieved the highest value on day 3 in cultivation at all tested glucose concentrations; whereas the maximum level of squalene production occurred on day 2 . The medium contained $4 \%$ glucose showed the highest biomass, squalene content and production compared to other glucose concentrations. Although, biomass, squalene content and production in the medium contained $2 \%$ glucose on day 2 is slightly lower than in the medium contained $4 \%$ glucose, the squalene content and production at $2 \%$ glucose on day 3 (up to 4.6 $\mathrm{mg} / \mathrm{g} \mathrm{DCW}$ and $38.8 \mu \mathrm{g} / \mathrm{L}$ ) were the highest compared to other glucose concentrations. Therefore, further analysis were operated using glucose concentration of $2 \%$.

Our obtained results similar with other groups published as well (Li et al., 2009; Patel et al., 2019). Patel et al. (2019) reported that the squalene contents of Schizochytrium mangrovei FB1, $S$. mangrovei FB2, $S$. mangrovei FB3, S. mangrovei, Aurantiochytrium sp. BR-MP4-A1, Aurantiochytrium sp. $18 \mathrm{~W}-13 \mathrm{a}$ were of $0.162,0.08,0.05,1.17,0.72$ and $198 \mathrm{mg} / \mathrm{g}$ of DCW at glucose concentration of $2 \%$ in flask cultivation. Compared to the strains in report of Pora et al. (2014), squalene production of Thraustochytrium sp. TN22 was much higher, except for Aurantiochytrium sp. 18 W-13a. 

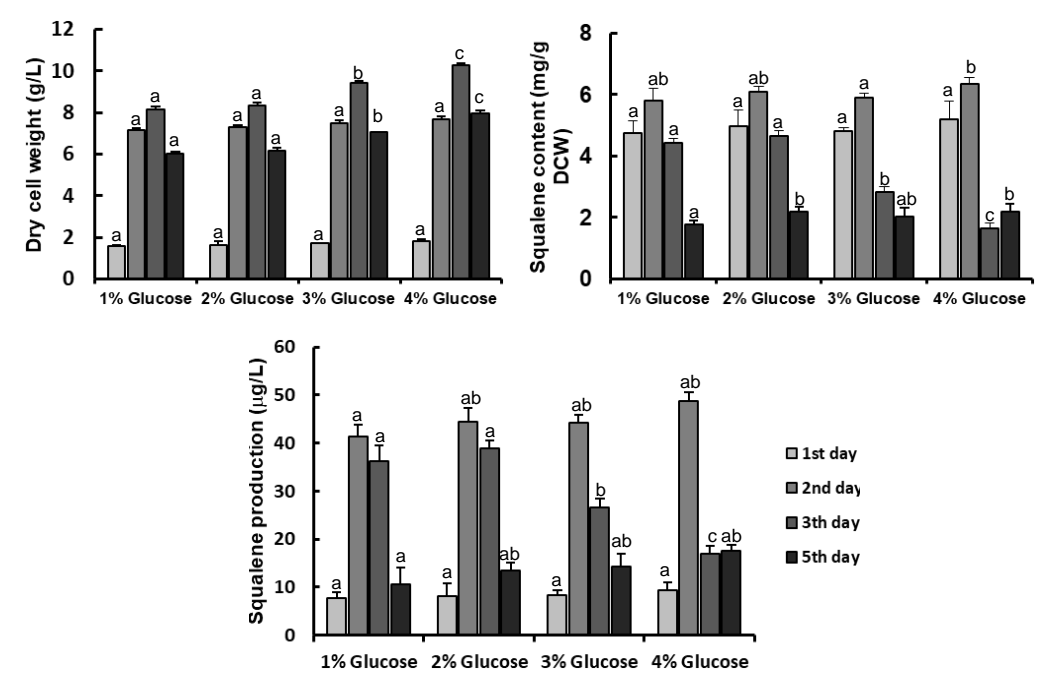

Figure 2. Effect of glucose concentrations on cell growth and squalene production in Thraustochytrium sp. TN22. Data represent the means \pm SE $(n=3)$. a, b, c: Values in a line not sharing a common superscript differ significantly at $P<0.05$

\section{Yeast extract concentration test}

The effect of concentrations of yeast extract on cell growth and squalene accumulation of Thraustochytrium sp. TN22 were also examined (Fig. 3). The cell growth was increased by increasing the concentration of yeast extract to $1.5 \%$. With all tested yeast extract concentration, the highest dry cell weight of TN22 strain was achieved on day 3, whereas its squalene content reached the maximum on day 2 in cultivation but decreased rapidly thereafter. The highest squalene content $(8.9 \mathrm{mg} / \mathrm{g}$ of DCW) obtained in the medium containing $0.25 \%$ yeast extract but the maximum squalene production was reached $48.9 \mathrm{mg} / \mathrm{L}$ in the medium containing $0.5 \%$ yeast extract. Thus, $0.5 \%$ of yeast extract was selected for subsequent experiment.
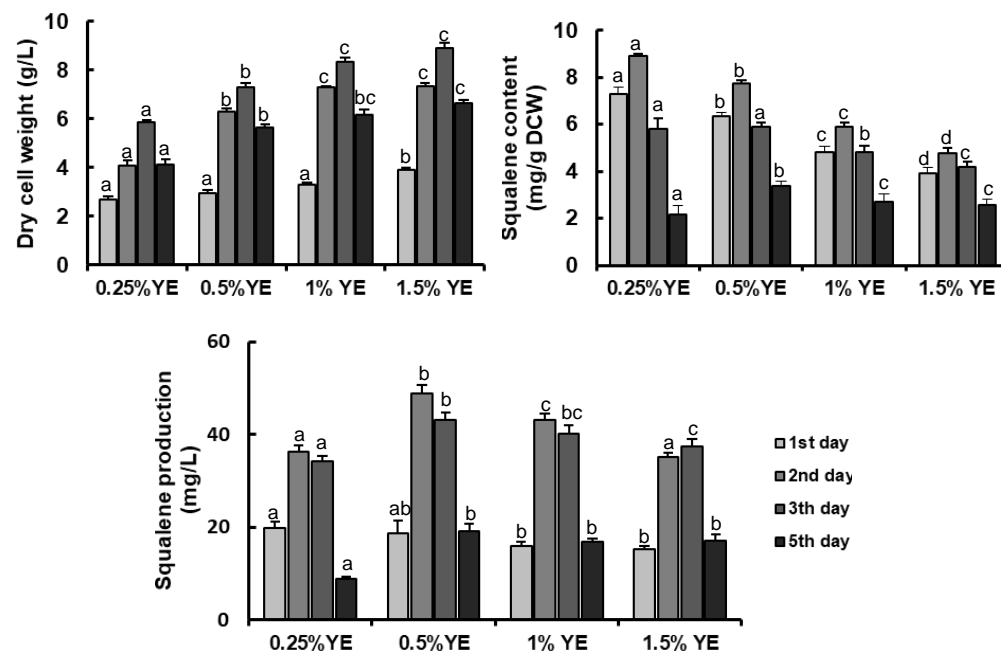

Figure 3. Effect of yeast extract concentrations on cell growth and squalene production in Thraustochytrium sp. TN22. Data represent the means $\pm \mathrm{SE}(\mathrm{n}=3)$. a, b, c, d: Values in a line not sharing a common superscript differ significantly at $P<0.05$ 


\section{Vitamin mixture test}

Recent studies showed that one of key parameters considering for increasing the production of squalene in species belonging thraustochytrids is the addition of vitamins, more precisely of vitamin $\mathrm{B}_{1}, \mathrm{~B}_{6}$ and especially of vitamin $B_{12}$ (Pora et al., 2014). Among that, vitamin $B_{12}$ would suggest its involvement as a cofactor of some of the key enzymes involved in squalene biosynthesis.
Vitamin $B_{1}$ would stimulate the leucine degradation pathway, which would increase the intracellular amount of squalene precursors, and vitamin $\mathrm{B}_{6}$, by modifying the action of cytochromes, would prevent squalene degradation (Pora et al., 2014). Therefore, we investigated the effect of the addition of vitamin mixture on cell growth and squalene production of Thraustochytrium sp. TN22 (Fig. 4).
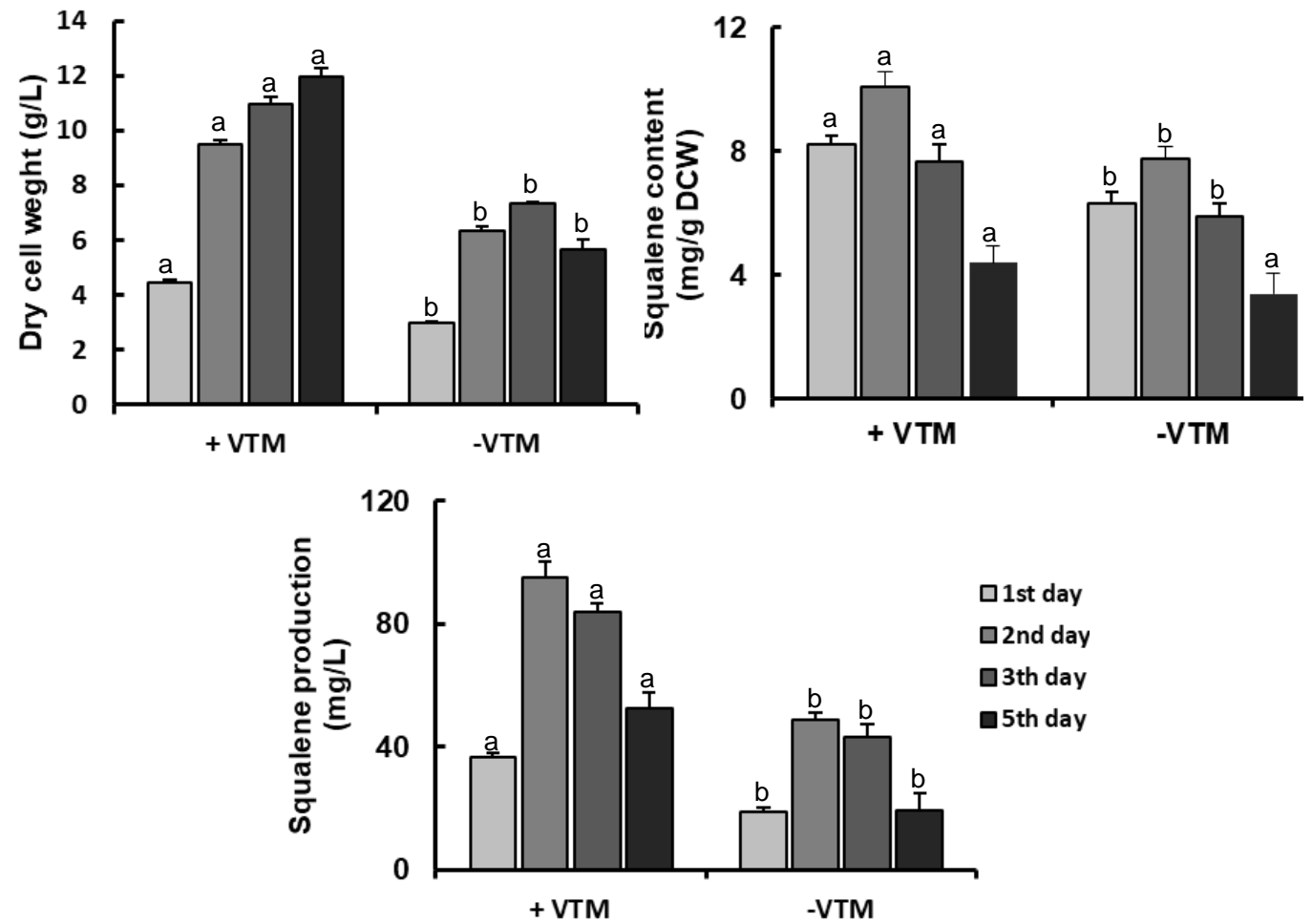

Figure 4. Effect of the addition of vitamin mixture on cell growth and squalene production in Thraustochytrium sp. TN22. Data represent the means $\pm \mathrm{SE}(\mathrm{n}=3)$. a, b: Values in a line not sharing a common superscript differ significantly at $P<0.05$

The effect of addition of vitamin mixture is remarkable. The DCW and squalene production in the addition of tested vitamin mixture significantly increased $2-3$ times higher than that in without adding vitamin mixture. Maximal dry cell weight was observed on day 5 in cultivation, while the highest squalene production was observed on day 2. This trend is in agreement with the report of Pora et al. (2014), Nguyen et al. (2017). Additionally, Nguyen et al. (2017) suggested that the increasing in biomass and squalene production in the medium containing vitamin mixture is due to vitamins enhanced the cells consuming the glucose in the system to increase the growth of cell and the production of squalene.

In comparison with fermented Schizochytrium strains in report of Pora et al. (2014) and Nguyen et al. (2017), squalene production of Thraustochytrium sp. TN22 was much lower, however, squalene content of the 
strain TN22 (9.9 mg/g of DCW) was higher compare those level in Schizochytrium sp. ATCC 20888 (4 mg/g of biomass) and Aurantiochytrium sp. ATCC PRA 276 (1.2 $\mathrm{mg} / \mathrm{g}$ of biomass) in the study of Pora et al. (2014). We suggested that the difference compared to the results obtained by Pora et al. (2014), Nguyen et al. (2017) may be due to the different characteristics of the different strains and the difference in culture scale.

Taken together, the highest squalene content and production by Thraustochytrium sp. TN22 were $9.9 \mathrm{mg} / \mathrm{g}$ DCW and 95.3 $\mathrm{mg} / \mathrm{mL}$, respectively with medium containing $2 \%$ glucose, $0.5 \%$ yeast extract and $0.14 \%$ vitamin mixture at $28{ }^{\circ} \mathrm{C}$ after 2 days of cultivation.

Extraction, purification and structural identification of squalene from the cell suspensions of Thraustochytrium sp. TN22

In here, we developed a simple and easy method for extraction of squalene from the cell suspensions of Thraustochytrium sp. TN22.

One of important factors in squalene extraction process is the rupturing of the cell membranes. According to Pora et al. (2014), cell membrane of thraustochytrids can be lysed easily in medium with $\mathrm{pH}=10$ at high temprature. Thefore, we first investigated the effect of alkaline medium and timedependance on the rupturing of the Thraustocytrium sp. TN22 cells. The cell suspensions of strain $\mathrm{TN} 22$ was adjusted to $\mathrm{pH}=10$ by $\mathrm{KOH} 45 \%$ and maintained for 1 , 2, 4, 6 and 8 hours at $60{ }^{\circ} \mathrm{C}$, stiring at $150 \mathrm{rpm}$ (Fig. 5). As shown in Fig. 5, the rupturing of cell membrane were in a time dependent manner. The amount of cell lysate was reached by $20 \%$ after $1 \mathrm{~h}, 40-50 \%$ after $2 \mathrm{~h}$, 60-70\% after 4 hours and almost the cell membranes were broken down after 6 hours. $\mathrm{We}$, therefore, suggested that the condition for completed cell lysis was in 6 hours.
$\mathbf{O h}$

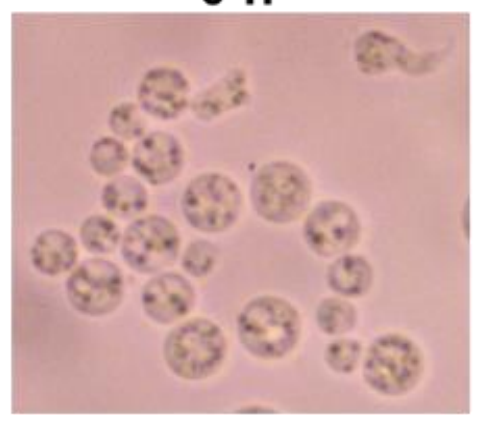

$4 \mathrm{~h}$

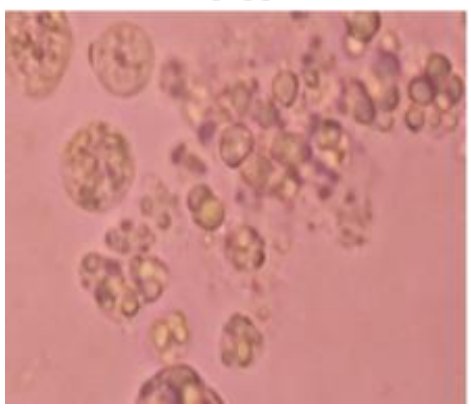

$1 \mathrm{~h}$

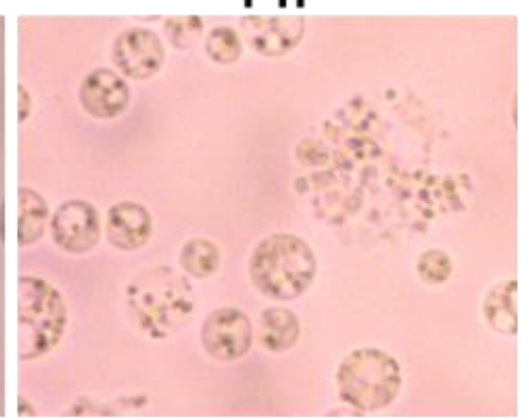

$6 \mathrm{~h}$

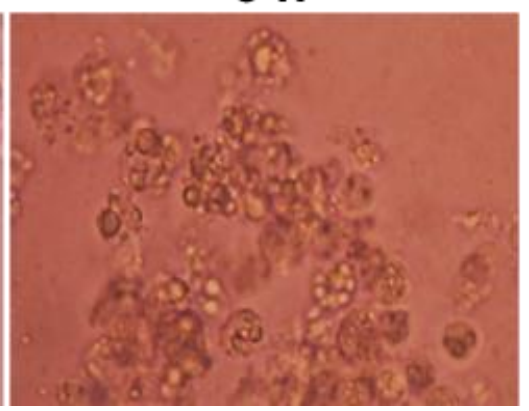

2 h

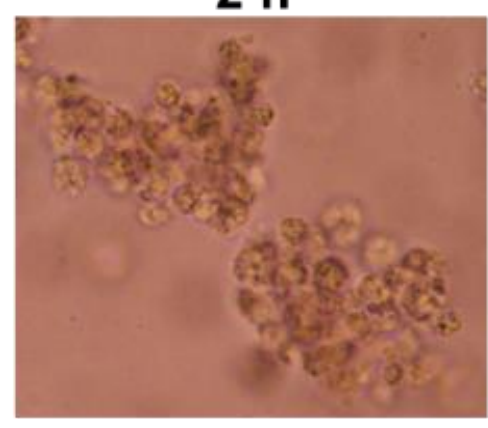

$8 \mathrm{~h}$

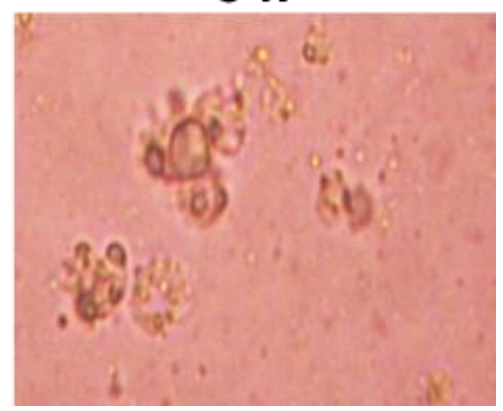

Figure 5. Morphology of Thraustochytrium sp. TN22 at the different times in alkaline treatment 
Squalene is an component in unsaponifiable lipid. Numerous studies indicated that unsaponifiable lipids from strains of the thraustochytrids can be separated from solvent systems such as nhexane; methanol: chloroform $(2: 1, \mathrm{v} / \mathrm{v})$, or petroleum ether ( $\mathrm{Lu}$ et al., 2003; Hoang et al., 2014; Pora et al., 2014). Therefore, we performed the effect of n-hexane; methanol: chloroform $(2: 1, \mathrm{v} / \mathrm{v})$, or petroleum ether on squalene extraction of cell lysates of Thraustochytrium sp. TN22 (Fig. 6).

As shown in Figure 6, the squalene content was significantly influenced by organic solvents. Squalene production was low in methanol: chloroform $(2: 1, \mathrm{v} / \mathrm{v})$ (up to $159.9 \mathrm{mg} / \mathrm{L})$, or petroleum ether $(135.2 \mathrm{mg} / \mathrm{L})$. In constract, when $\mathrm{n}$-hexane was used, high concentration of squalene was obtained with the value of $178.1 \mathrm{mg} / \mathrm{L}$ by HPLC analysis.

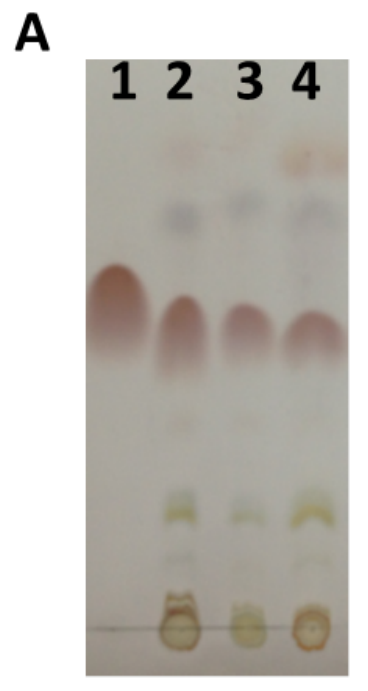

\section{B}

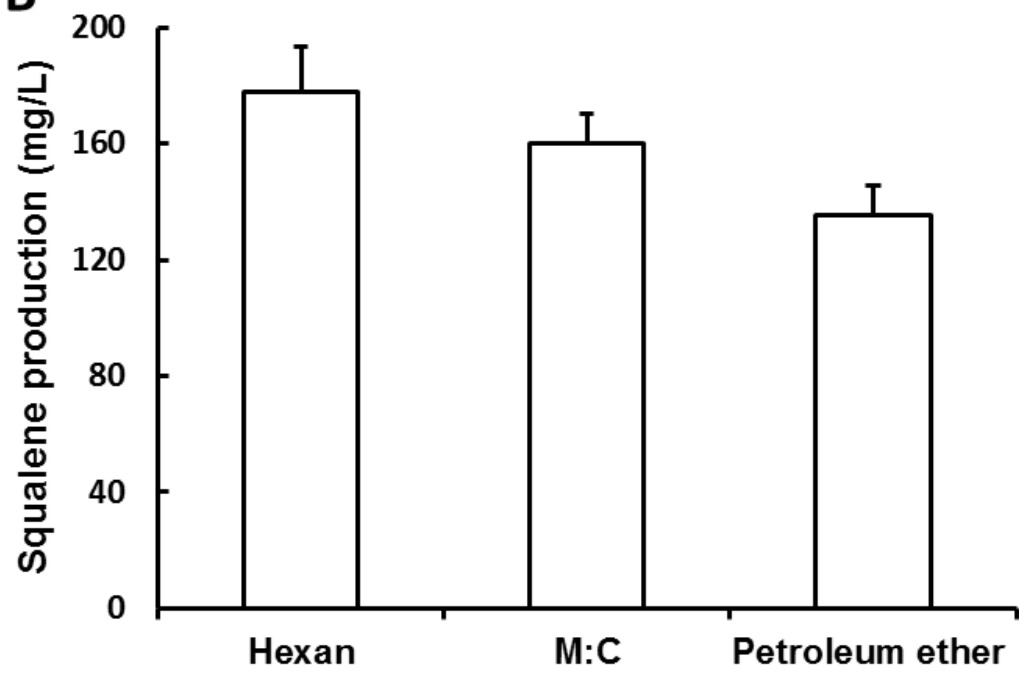

Figure 6. The effect of organic solvent systems on the extraction of squalene from cell lysates of Thraustochytrium sp. TN22. A: TLC analysis of extracted squalene from cell lysates where lane 1, squalene standard; lane 2, extrated squalene by n-hexane; lane 3, extrated squalene by methanol: chloroform (M:C, 2:1, v/v); lane 4, extrated squalene by petroleum ether. B: Squalene production. Squalene content was assessed by HPLC analysis

To verify its structure, the squalene obtained after extraction process was purified by silica gel column chromatography. Squalene was sucessfuly separated from n-hexane fraction. Several fractions rich in squalene were detected by TLC with the Sigma standard, combined and then the solvent was evaporated by rotary evaporation to yield a colorless liquid. The squalene in these fractions was then analyzed by HPLC. According to TLC and HPLC data (Fig. 7), extracted squalene was shown to be good purity (90\%) with a recovery yield of $70 \%$.
The structure of the squalene from cell suspention was further confirmed by its ${ }^{1} \mathrm{H}$ and ${ }^{13} \mathrm{C}$ NMR spectroscopic data (Fig. 8). The ${ }^{1} \mathrm{H}$ NMR $\left(500 \mathrm{MHz}, \mathrm{CDCl}_{3}\right.$ ) (Fig. 8A) showed methyl groups at $\delta 1.60(\mathrm{~s}, 18 \mathrm{H})$ and $\delta 1.68(\mathrm{~s}, 6 \mathrm{H})$, methylene groups at $\delta$ 1.99-2.02 (m, 20H), and internal vinyl signals at $\delta 5.08-5.15(\mathrm{~m}, 6 \mathrm{H})$. The ${ }^{13} \mathrm{C}$ NMR (125 MHz, $\mathrm{CDCl}_{3}$ ) (Fig. 8B) showed methyl carbons at $\delta 16.00,16.04,17.67$, methylene carbons at $\delta 25.69,26.69,26.80$, $28.30,39.75,39.77$, and double bond carbons at $\delta 124.30,124.33,124.44,131.22$, $134.89,135.10$. The NMR spectra were in 
complete agreement with those of the standard squalene material and consistent with the published literature Poucher and Behnke (1993).
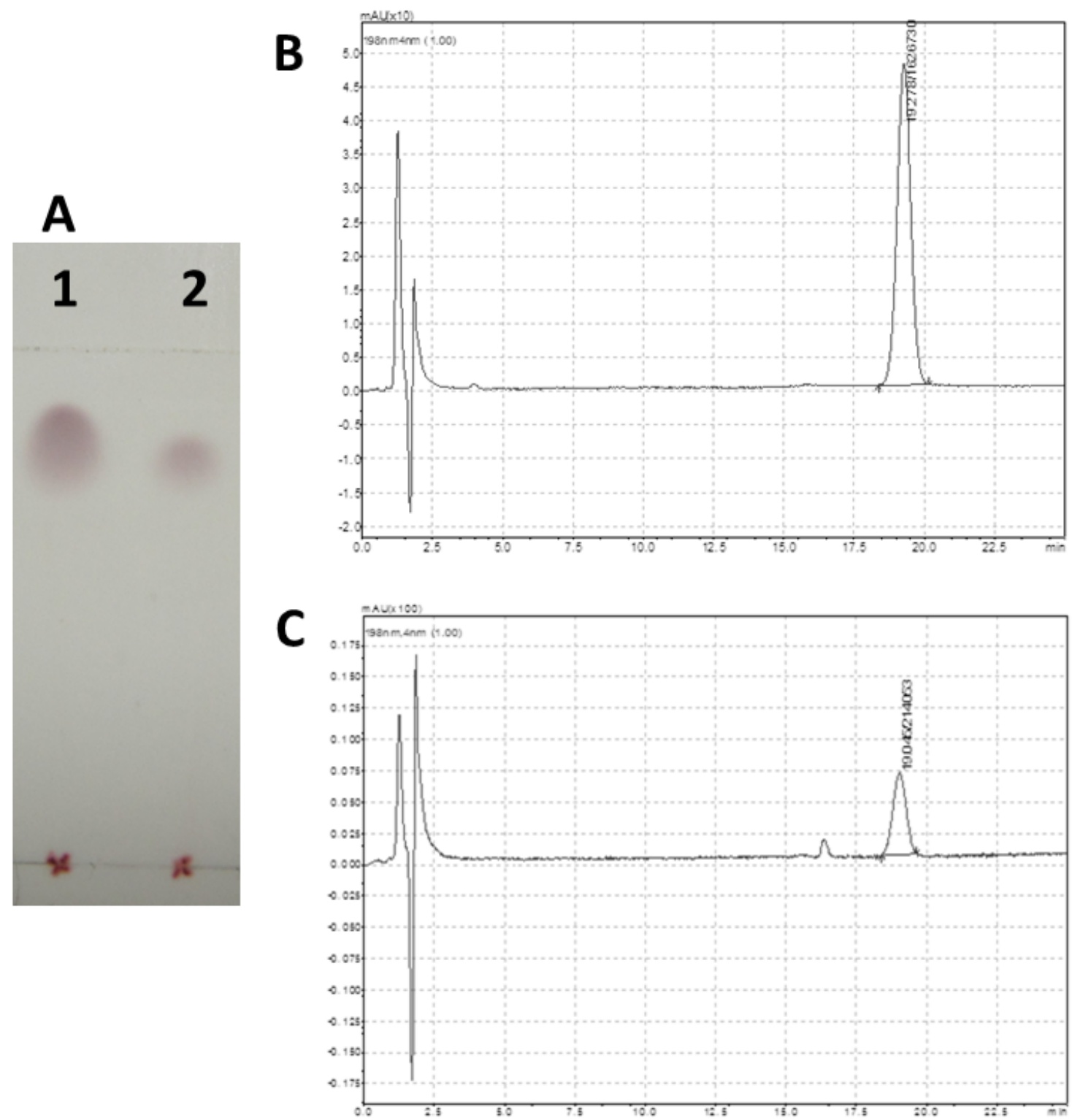

Figure 7. Thin-layer chromatography (A) and typical chromatogram of purified squalene from standard (B) and Thraustochytrium sp. TN22 (C). In A: Lane 1, squalene standard; lane 2, squalene purified from cell suspension of Thraustochytrium sp. TN22

Taken together, we suggested that the optimal process for extraction of squalene for $100 \mathrm{~g}$ biomass/L of cell suspension of Thraustochytrium sp. TN22 was cell lysate at alkaline medium $(\mathrm{pH}=10)$, at $60{ }^{\circ} \mathrm{C}$ for $6 \mathrm{~h}$ with $1 \mathrm{~V}$ of each extraction solvents as ethanol and n-hexane. Squalene was then purified on silica gel column 60 using a mobile phase consisting of $n$-hexane at a flow rate of approximately $1.0 \mathrm{~mL} / \mathrm{min}$. This method yielded $178.1 \mathrm{mg}$ squalene at $90 \%$ purity from $100 \mathrm{~g}$ of biomass. 

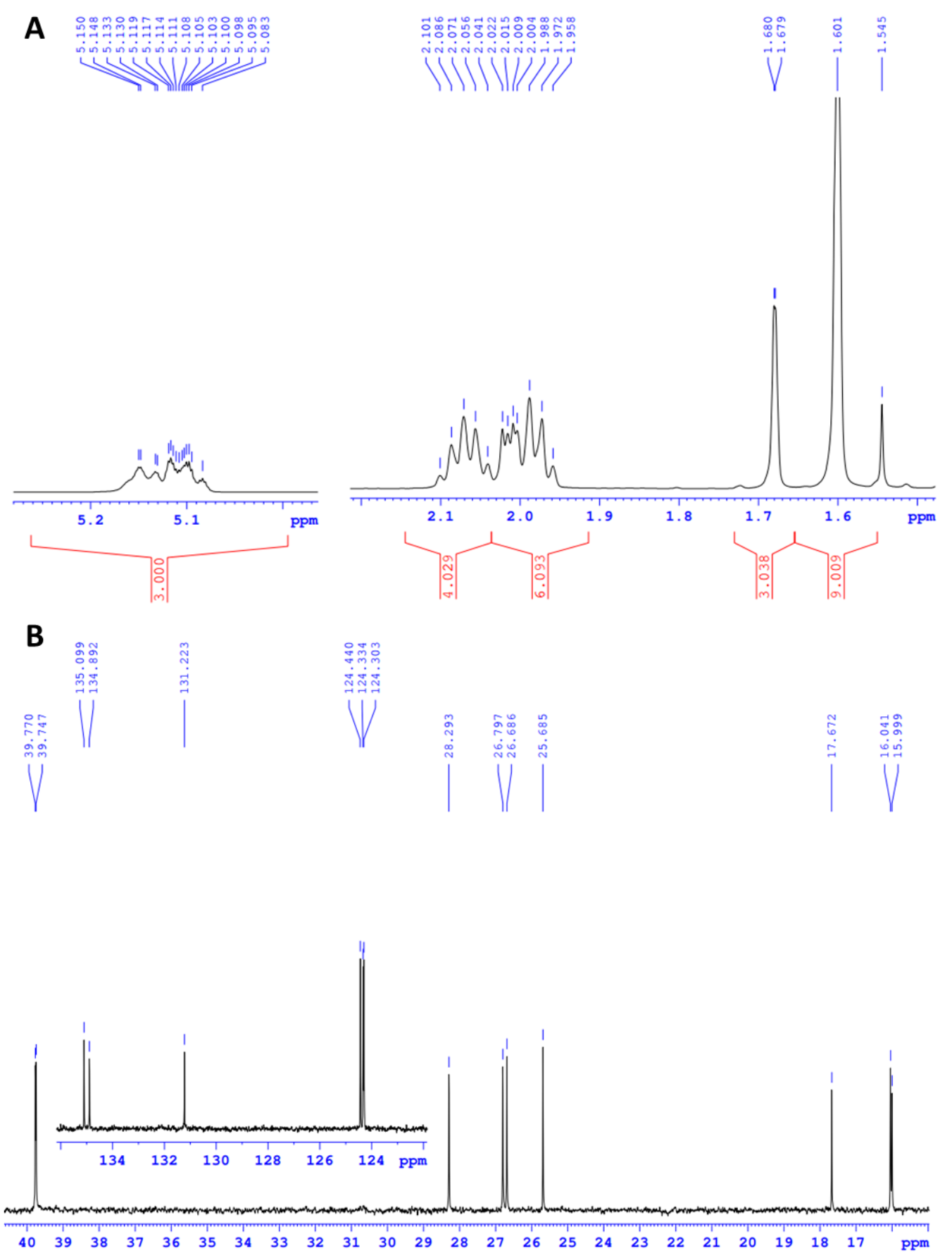

Figure 8. NMR spectra of purified squalene from cell suspension of Thraustochytrium sp. TN22. ${ }^{1} \mathrm{H}$ NMR (500 MHz, $\mathrm{CDCl}_{3}$ ) spectra (A). ${ }^{13} \mathrm{C} \mathrm{NMR}\left(125 \mathrm{MHz}, \mathrm{CDCl}_{3}\right)$ spectra (B)

\section{CONCLUSION}

In the present study, the cultivation parameters for attaining high squalene accumulation by Thraustochytrium sp. TN22 in flasks were optimized. The highest squalene content $(9.9 \mathrm{mg} / \mathrm{g}$ of $\mathrm{DCW})$ were 
obtained with $2 \%$ glucose, $0.5 \%$ yeast extract and $0,14 \%$ mixture of vitamins at $28{ }^{\circ} \mathrm{C}$ in day 2 of cultivation. In addition, the simple method was successful developed to separate and purify squalene $90 \%$ purity and $70 \%$ revovery of yield.

Acknowledgements: This research is funded by Vietnam Academy of Science and Technology (VAST.02.03/19-20 for Dr. Hoang Thi Minh Hien, 2019-2020.

\section{REFERENCES}

Bligh E. G., Dyer W. J., 1956. A rapid method of total lipid extraction and purification. Can. J. Biochem. Physiol., 37(8): 911-917.

Bajpai P. K., Bajpai P., Ward O. P., 1991. Production of docosahexaenoic acid by Thraustochytrium aureum. Appl. Microbiol. Biotechnol., 35: 706-710.

Chen G., Fan K. W., Lu F. P., Li Q., Aki T., Chen F., Jiang Y., 2010. Optimization of nitrogen source for enhanced production of squalene from thraustochytrid Aurantiochytrium sp. New Biotechnology, 27: 382-389.

Dang Diem Hong, Hoang Thi Lan Anh, 2016. New heterotrophic marine microalgae Labyrinthula, Schizochytrium, Thraustochytrium in Vietnam: Opportunities and Challenges. Natural Sciences and Technology Publishing House, pp. 626. (in Vietnamese).

Dinh Thi Ngoc Mai, Nguyen Cam Ha, Le Thi Thom, Dang Diem Hong, 2013. Initial studies on squalene from some marine microalgae isolated in Vietnam. Journal of Biology, 35(3): 333-341. (in Vietnamese with English summary).

Hoang L. A. T., Nguyen H. C., Le T. T., Hoang T. H. Q., Pham V. N., Hoang M. H. T., Ngo H. T. T., Hong D. D., 2018. Different fermentation strategies by Schizochytrium mangrovei strain PQ6 to produce feedstock for exploitation of squalene and omega-3 fatty acids. $J$. Phycol., 54(4): 550-556.
Hoang M. H., Ha N. C., Thom L. T., Tam L. T., Anh H. T., Thu N. T., Hong D. D., 2014. Extraction of squalene as valueadded product from the residual biomass of Schizochytrium mangrovei PQ6 during biodiesel producing process. J. Biosci. Bioeng., 118(6): 632-639.

Hoang Thi Lan Anh, Dinh Thi Ngoc Mai, Ngo Thi Hoai Thu, Dang Diem Hong., 2010. Isolation of new heterotrophic marine microalga rich DHA and carotenoid strain belong to Thraustochytrium genus from Thi NaiBinh Dinh saltmash lagoon. Vietnam Journal of Biotechnology, 8: 459-465. (in Vietnamese with English summary).

Jiang Y., Fan K. W. and Wong R. T. Y., 2004. Fatty acids composition and squalene content of the marine microalga Schizochytrium mangrovei. J. Agric. Food. Chem., 52: 1196-1200.

Lee C. K. J., Nichols C. M., Blackburn S. I., Dunstan G. A., Koutoulis A., Nichols P. D., 2014 Comparison of Thraustochytrids Aurantiochytrium sp., Schizochytrium sp., Thraustochytrium sp., and Ulkenia sp. for production of biodiesel, long-chain omega-3 oils, and exopolysaccharide. Mar. Biotechnol., 16(4): 396-411.

Li Q., Chen G., Fan K. W., Lu F., Aki T., Jiang Y., 2009. Screening and characterization of squalene-producing thraustochytrids from Hong Kong mangroves. J. Agric. Food Chem., 57(10): 4267-4272.

Lu H. T., Jiang Y., Chen F., 2003. Preparative separation and purification of squalene from the microalga Thraustochytrium ATCC 26185 by high-speed countercurrent chromatography. J. Chromatogr. A., 994(1-2): 37-43.

Nakazawa A., Matsuura H., Kose R., Kato S., Honda D., Inouye I., Kaya K., Watanabe M. M., 2012. Optimization of culture conditions of the thraustochytrid Aurantiochytrium sp. strain $18 \mathrm{~W}-13$ a for squalene production. Bioresour. Technol., 109: 287-291. 
Nguyen Cam Ha, Hoang Thi Minh Hien, Le Thi Thom, Hoang Thi Huong Quynh, Dang Diem Hong., 2017. Optimization of fermentation conditions for squalene production by heterotrophic marine microalgae Schizochytrium mangrovei PQ6. Journal of Biology, 39(3): 449-458.

Otagiri M., Khalid A., Moriya S., Osada H., Takahashi S., 2017. Novel squaleneproducing thraustochytrids found in mangrove water. Biosci. Biotechnol. Biochem., 81(10): 2034-2037.

Patel A., Rova U., Christakopoulos P., Matsakas L., 2019. Simultaneous production of DHA and squalene from Aurantiochytrium sp. grown on forest biomass hydrolysates. Biotechnol. Biofuels, 12: 255.

Pollier J., Vancaester E., Kuzhiumparambil U., Vickers C. E., Vandepoele K., Goossens A., et al., 2019. A widespread alternative squalene epoxidase participates in eukaryote steroid biosynthesis. Nat. Microbiol., 4: 226-33.

Popa O., Băbeanu N. E., Popa I., Niță S., Dinu-Pârvu C. E., 2015. Methods for obtaining and determination of squalene from natural sources. Biomed. Res. Int., pp. 367202.
Pora B., Qian Y., Caulier B., Comini S., Looten P., Segueilha L., 2014. Method for the preparation and extraction of squalene from microalgae. Patent US20140088201.

Pouchert C. J., Behnke J., 1993. The Aldrich Library of 13C and 1H FTNMR Spectra. Aldrich Chemical Co., Milwaukee, WI., 46.

Spanova M., Daum G., 2011. Squalenebiochemistry, molecular biology, process biotechnology, and applications. Eur. J. Lipid Sci. Technol., 113: 1299-1320.

Shene C., Garcés M., Vergara D., Peña J., Claverol S., Rubilar M., Leyton A, 2019. Production of lipids and proteome variation in a chilean Thraustochytrium striatum strain cultured under different growth conditions. Mar. Biotechnol. (NY)., 21(1):99-110.

Tran T. L., Miranda A. F., Gupta A., Puri M., Ball A. S., Adhikari B., Mouradov A., 2020. The nutritional and pharmacological potential of new Australian thraustochytrids isolated from mangrove sediments. Mar. Drugs, 18: 151.

Xie Y., Sen B., Wang G., 2017. Mining terpenoids production and biosynthetic pathway in thraustochytrids. Bioresour. Technol., 244: 1269-80. 